\title{
ESTIMATION OF OPTIMAL OBESITY CUT-OFFS AMONG TRIPURI AND HALAM WOMEN OF TRIPURA, NORTHEAST INDIA
}

\author{
Rima Chaudhuri, Priyanka Das, Pranabesh Sarkar, \\ Diptendu Chatterjee, Arup Ratan Bandyopadhyay \\ Department of Anthropology, University of Calcutta, Kolkata, West Bengal, India
}

\begin{abstract}
Obesity is one of the risk assessments for various non-communicable diseases (NCDs), while anthropometric measurements are one of the measures of obesity, which has been demonstrated as a time-tested important technique for risk assessment of NCDs. Due to variation of anthropometric measurements, it seems difficult to classify obesity using world cut-offs in different population groups.

The objective of the present study is to discern the population-specific obesity cut-offs and the best obesity predictor among two indigenous ethnic groups (Tripuri and Halam women) of Tripura, North East India.

The subjects of the present study were 88 Tripuri and 98 Halam adult women whose anthropometric measurements were obtained by using standard techniques. The area under curve (AUC) and Youden index (YI) were used to evaluate the performance of each anthropometric adiposity indicator as well as optimal obesity cut-offs.

The age and waist-hip ratio (WHR) was significantly higher $(\mathrm{p}<0.05)$ in Tripuris compared to Halams. However, no significant $(p>0.05)$ differences were observed in obesity categorized by body mass index (BMI) using the WHO 2004 cut-off between the populations. Waist stature ratio (WSR) $(\mathrm{AUC}=0.959)$ and waist circumference $(\mathrm{WC})(\mathrm{AUC}=0.804)$ were better obesity predictors for Halams and Tripuris respectively. The present study envisaged the optimal cut-off points, which were $84.95 \mathrm{~cm}$ for WC, $96.45 \mathrm{~cm}$ for hip circumference (HC), 29.95\% for the percentage of body fat (PBF), 0.89 for WHR, 0.57 for WSR and 1.27 for conicity index (CI) in Halams, while for the Tripuris, the optimal cut-off points were $89.6 \mathrm{~cm}$ for WC, $97.5 \mathrm{~cm}$ for $\mathrm{HC}$, 33.1\% for PBF, 0.95 for WHR, 0.55 for WSR and 1.02 for CI.
\end{abstract}


In conclusion, the present study indicated the optimal anthropometric cut-offs which could be the redefined the parameters for assessment of obesity in Halam and Tripuri women.

Keywords: obesity; cut-offs; ROC; Youden Index; Tripuri; Halam; Northeast India.

\section{INTRODUCTION}

Obesity is a metabolic disorder characterized by excess body fat mass accumulation $[1,2]$. The prevalence of obesity has increased in both developed and developing countries due to modernization, urbanization, and an economic shift in lifestyle [3]. Throughout the world, 600 million adults are obese [4], which is causing certain chronic and non-communicable diseases (NCDs) like diabetes and cardiovascular disease $[2,5]$. Anthropometric measurements are one of the measures for obesity and has proved to be an important technique for risk assessment of NCDs. Body mass index (BMI) has widely been used all over the world for assessment of general obesity. Subsequently, waist circumference (WC), waist hip ratio (WHR), waist stature ratio (WSR) and percentage of body fat (PBF) have also been used as better predictors of obesity than BMI for evaluation of the risk of metabolic syndromes $[1,6,7]$. The majority of studies have used world cut-offs for assessment of obesity and its related effects on NCDs [8]. Obesity assessment has been misclassified in several populations because of using worldwide cut-offs $[9,10]$, which is misleading in risk assessment for NCDs [10]. India is a land of heterogenous populations with enormous genetic, cultural, and linguistic diversity [11]. Therefore, the diversity of populations is expressed through their phenotypic character like fat patterning [12]. Therefore, worldwide/generalized cut-offs might not be suitable for classifying obesity appropriately in such diversified populations. For that reason, determination of population-specific cut-offs might be helpful for better understanding of the obesity pattern and its related consequences. On this background, the objective of the present study was to discern the population-specific obesity cut-offs and best obesity predictor among Tripuri and Halam women of Tripura, North East India. 


\section{MATERIALS AND METHODS}

The subjects of the present study were adult female participants from among Halams (98) and Tripuris (88) of West Tripura, Northeast India. There are 19 indigenous populations in Tripura in the North-East region of India. The indigenous populations of Tripura are usually divided into two major groups aborigines and immigrants. Both populations considered in the present study belong among the aborigines [13]. Halams belong to Kuki-chin tribes and linguistically within the Tibeto-Burman linguistic family. Halams are divided into several subclans like Koloi, Korbong, Kaipeng, Bong, Sakachep, Thangachep, Dab or Nabin, Bongcher, Molsom, Rupini, Rangkhowl, Chorai, Lankai, Kaireng (Darlong), Ranglong, Marchafang and Saihmar. Tripuris are the largest tribal community in Tripura. Tripuris are of Indo-Mongoloid origin and linguistically belong to the Tibeto-Burman linguistic family. They use the Kok-Borok dialect for speaking [13]. Informed consent was obtained from each participant prior to the study. Measurements like height (HT), weight (WT), hip circumference (HC), waist circumference (WC) were taken from each participant using the standard anthropometric protocol [14].

BMI [WT $\left.(\mathrm{kg}) / \mathrm{HT}\left(\mathrm{m}^{2}\right)\right]$, WHR [WC $\left.(\mathrm{cm}) / \mathrm{HC}(\mathrm{cm})\right]$, WSR [WC $(\mathrm{cm}) /$ $\mathrm{HT}(\mathrm{cm})]$ and CI (conicity index) [WC $(\mathrm{m}) /[(0.109) \times \sqrt{ }\{\mathrm{WT}(\mathrm{kg}) / \mathrm{HT}(\mathrm{m})\}]$ were calculated using the standard formulae $[15,16,17,18]$. The percentage of body fat (PBF) was assessed by a Rossmax fat monitor with a scale (model WF260) following the instruction manual. The participants were categorized as of normal weight (BMI $\left.>18.5-22.9 \mathrm{~kg} / \mathrm{m}^{2}\right)$, overweight $\left(\mathrm{BMI} \geq 23-27.5 \mathrm{~kg} / \mathrm{m}^{2}\right)$ and obese (BMI $\left.\geq 27.6 \mathrm{~kg} / \mathrm{m}^{2}\right)$ as per Asian cut-offs [19].

Apart from descriptive statistics (mean \pm SD) and inferential statistics to compare the mean values of continuous variables, the Mann-Whitney test was performed. For inter-group comparisons of categorical variables, chi-square tests were performed. Receiver-operating characteristic (ROC) curve analysis and the area under the curve (AUC) were used to identify the optimal anthropometric obesity cut-off values (Figure 1). Cut-offs were determined using the highest value of the Youden Index. The data were analysed by the Statistical Package for Social Science (SPSS, Inc., Chicago, IL; version, 16.00). The cut-off was set as $\mathrm{p}=0.05$.

\section{RESULTS}

Age and WHR were significantly higher $(\mathrm{p}<0.05)$ in Tripuris compared to Halams (Table 1). However, no significant $(p>0.05)$ differences in obesity were 
observed between the Tripuris and the Halams when categorized by BMI using the WHO 2004 cut-off (Table 2).

AUC was used to evaluate the performance of each anthropometric obesity indicator for screening of obesity (Table 3 and Figure 1). WSR (AUC $=0.959$ ) and WC $($ AUC $=0.926)$ exhibited the largest AUC in Halams. HC $($ AUC $=0.850)$ and WC $(A U C=0.804)$ demonstrated the largest AUC in Tripuris. Significantly $(\mathrm{p}<0.05)$ higher AUC was found for WC, HC, PBF, WHR, WSR and CI in Halams. On the other hand, significantly $(\mathrm{p}<0.05)$ higher AUC was found for WC, HC, PBF and WSR in Tripuris. Furthermore, population-specific optimal cut-offs for obesity were identified through the Youden Index and are presented in Table 4. Eventually, the optimal cut-off points were found to be $84.95 \mathrm{~cm}$ for WC, $96.45 \mathrm{~cm}$ for HC, $29.95 \%$ for PBF, 0.89 for WHR, 0.57 for WSR and 1.27 for the conicity index in Halams. However, in case of Tripuris, the optimal cut-off points were revealed as $89.6 \mathrm{~cm}$ for WC, $97.5 \mathrm{~cm}$ for $\mathrm{HC}, 33.1 \%$ for PBF, 0.95 for WHR, 0.55 for WSR and 1.02 for the conicity index.

Table 1. Characteristics of the studied population

\begin{tabular}{cccc}
\hline VARIABLES & $\begin{array}{c}\text { HALAM } \\
\text { Mean (SD) } \\
(\mathbf{n}=98)\end{array}$ & $\begin{array}{c}\text { TRIPURI } \\
\text { Mean (SD) } \\
(\mathbf{n}=88)\end{array}$ & $p$ \\
\hline AGE $($ years) & $44.89(17.40)$ & $39.32(14.74)$ & $<0.05$ \\
\hline HEIGHT $(\mathrm{cm})$ & $154.09(7.32)$ & $156.21(8.83)$ & $>0.05$ \\
\hline WEIGHT $(\mathrm{kg})$ & $54.27(8.89)$ & $56.48(12.93)$ & $>0.05$ \\
\hline$W C(\mathrm{~cm})$ & $79.38(10.21)$ & $81.24(9.19)$ & $>0.05$ \\
\hline$H C(\mathrm{~cm})$ & $91.26(6.45)$ & $91.41(8.13)$ & $>0.05$ \\
\hline PBF $(\%)$ & $24.83(13.86)$ & $26.07(7.25)$ & $>0.05$ \\
\hline$W H R$ & $0.86(0.07)$ & $0.89(0.08)$ & $<0.05$ \\
\hline$W S R$ & $0.51(0.07)$ & $0.52(0.05)$ & $>0.05$ \\
\hline$B M I\left(\mathrm{~kg} / \mathbf{m}^{2}\right)$ & $22.85(3.45)$ & $22.98(3.97)$ & $>0.05$ \\
\hline CONICITY INDEX & $1.22(0.10)$ & $1.24(0.14)$ & $>0.05$ \\
\hline
\end{tabular}

*Mann-Whitney test, $p<0.05$

Table 2. Classification of studied participants by BMI categories (WHO, 2004)

\begin{tabular}{lccc}
\hline & $\begin{array}{c}\text { HALAM } \\
(\mathbf{n}=98)\end{array}$ & $\begin{array}{l}\text { TRIPURI } \\
(\mathbf{n}=88)\end{array}$ & $\boldsymbol{p}$ \\
\hline NORMAL & $56(57.14)$ & $46(52.27)$ & \multirow{2}{*}{$>0.05$} \\
\cline { 1 - 3 } OVERWEIGHT & $31(31.63)$ & $29(32.95)$ & \\
\hline OBESE & $10(10.20)$ & $12(13.63)$ & \\
\hline
\end{tabular}

Figures in parenthesis indicate percentage. 
Table 3. ROC (receiver operating characteristics) curve for anthropometric obesity indicators using the BMI classification by WHO, 2004.

\begin{tabular}{ccccc}
\hline & $\begin{array}{c}\text { Area under the ROC } \\
\text { curve }(95 \% \mathrm{Cl})\end{array}$ & & $\begin{array}{c}\text { Area under the ROC } \\
\text { curve }(95 \% \mathrm{CI})\end{array}$ & \\
VARIABLES & HALAM $(\mathbf{n}=98)$ & $\boldsymbol{p}$ & TRIPURI $(\mathbf{n}=88)$ & $p$ \\
\hline$W C(\mathrm{~cm})$ & $0.926(0.872-0.981) *$ & $<0.05$ & $0.804(0.638-0.971) *$ & $<0.05$ \\
\hline$H C(\mathrm{~cm})$ & $0.847(0.732-0.962) *$ & $<0.05$ & $0.850(0.691-1.009) *$ & $<0.05$ \\
\hline$P B F(\%)$ & $0.771(0.596-0.946) *$ & $<0.05$ & $0.707(0.546-0.868) *$ & $<0.05$ \\
\hline$W H R$ & $0.855(0.742-0.968) *$ & $<0.05$ & $0.561(0.386-0.736)$ & $>0.05$ \\
\hline$W S R$ & $0.959(0.920-0.997) *$ & $<0.05$ & $0.739(0.551-0.927) *$ & $<0.05$ \\
\hline Conicity index & $0.741(0.592-0.891)^{*}$ & $<0.05$ & $0.393(0.215-0.572)$ & $>0.05$ \\
\hline
\end{tabular}

$p$-values for rejecting the null of $A U C=0.05$

ROC Curve

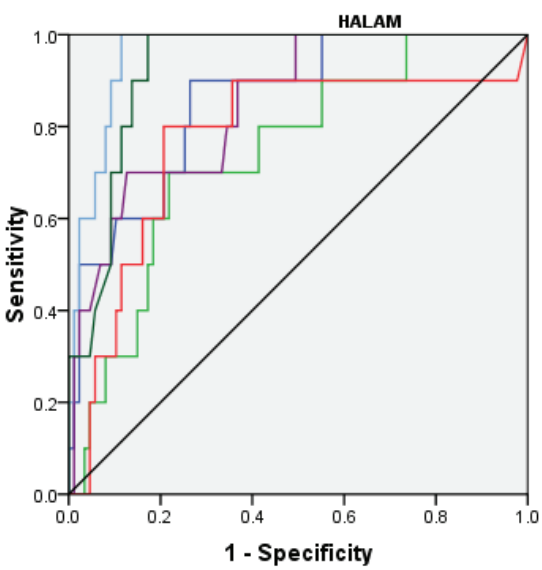

Source of the Curve

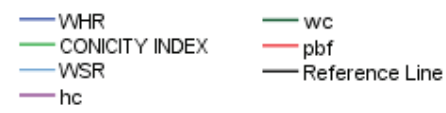

ROC Curve

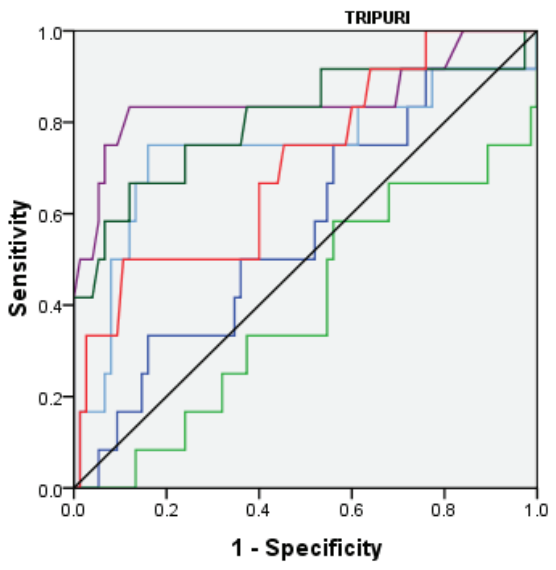

Source of the Curve

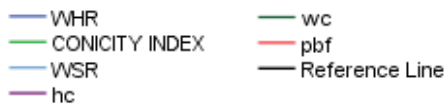

Figure 1. ROC curve of anthropometric variables pertaining to obesity in Halam and Tripuri women. 
Table 4. Optimal cut off points for the studied population.

\begin{tabular}{|c|c|c|c|c|c|c|c|c|}
\hline \multirow[b]{2}{*}{ VARIABLES } & \multicolumn{3}{|c|}{ HALAM $(n=98)$} & \multicolumn{5}{|c|}{ TRIPURI $(n=88)$} \\
\hline & 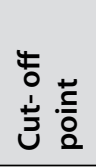 & 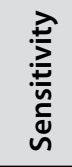 & 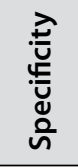 & $\begin{array}{l}\frac{c}{d} \\
\frac{0}{2} \\
\frac{0}{0} \\
\text { 으 }\end{array}$ & 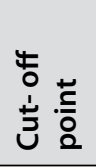 & 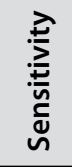 & 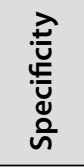 & $\begin{array}{l}\frac{c}{0} \\
\frac{0}{0} \\
\stackrel{0}{0} \\
\stackrel{0}{0}\end{array}$ \\
\hline$W C(\mathrm{~cm})$ & 84.95 & 1.00 & 0.83 & 0.83 & 89.6 & 0.66 & 0.88 & 0.54 \\
\hline$H C(\mathrm{~cm})$ & 96.45 & 0.70 & 0.87 & 0.57 & 97.5 & 0.83 & 0.88 & 0.71 \\
\hline PBF (\%) & 29.95 & 0.80 & 0.79 & 0.59 & 33.1 & 0.50 & 0.89 & 0.39 \\
\hline$W H R$ & 0.89 & 0.90 & 0.73 & 0.63 & 0.95 & 0.33 & 0.84 & 0.17 \\
\hline WSR & 0.57 & 1.00 & 0.88 & 0.88 & 0.55 & 0.75 & 0.82 & 0.57 \\
\hline Conicity index & 1.28 & 0.70 & 0.77 & 0.47 & 1.02 & 0.75 & 0.01 & 0.24 \\
\hline
\end{tabular}

\section{DISCUSSION}

Composition and distribution of body fat is important for understanding the adverse health outcomes [20] in different ethnic groups [21,22]. The present study identified obesity among Tripuri and Halam females by using ROC generated optimal cut-offs [23]. WSR (cut-off 0.57) and HC (cut-off 0.85) were identified as better obesity predictors for Halams and Tripuris respectively. These findings partially agreed with earlier studies among Ethiopians [24] and Javanese [25] where WC and WSR were used as strong predictors of obesity. Ethiopians and Indians have comparatively higher body fat percentages in respect of lower or the same level of BMI than Caucasians [24]. Moreover, the identified optimal cut-off points for WC, WSR and WHR among the Tripuri and the Halam populations were comparatively higher than Asian Indian [26], Joint Scientific Statement (JIS) [27], Javanese [25] and Ethiopian [24] cut-off values. On the other hand, higher WC cut-off value compared to Halams and Tripuris was found in Brazilian women [28]. The inconsistency of cut-off values has been obtained in different populations primarily due to variability of regional fat distribution [24, 26].

Group differences in obesity cut-offs were also observed between the Tripuri and the Halam populations. The cut-off points for obesity parameters (except WSR and CI) were comparatively higher in Tripuri than Halams due to differential body fat distribution. Examination of patterns of fat distribution revealed greater amount of fat deposition in the truncal/central region of Tripuris compared to that of Halams irrespective of BMI and PBF, and that might lead to higher cut-off points for Tripuris. 
Discrepancy of results was found in terms of optimal obesity cut-offs and strong obesity predictors, which requires population- or ethnic-specific cutoffs. Therefore, the optimal anthropometric cut-offs envisaged in the present study may redefine the parameters for assessment of obesity in Halam and Tripuri women.

\section{ACKNOWLEDGMENTS}

The authors are grateful to the participants of the present study.

\section{FUNDING}

The present study was supported by UPE-II and BI (5) \& (6) grants.

\section{REFERENCES}

1. Zeng Q., Dong S.Y., Sun X.N., Xie J., Cui Y. (2012). Percent body fat is a better predictor of cardiovascular risk factors than body mass index. Braz J Med Biol Res, 45, 591-600. https://doi.org/10.1590/S0100-879X2012007500059

2. Cercato C., Fonseca F.A. (2019). Cardiovascular risk and obesity. Diabetol Metab Syndr, 11, 74-88. https://doi.org/10.1186/s13098-019-0468-0

3. Yu J., Tao Y., Tao Y., Yang S., Yu Y., Li B., Jin L. (2016). Optimal cut-off of obesity indices to predict cardiovascular disease risk factors and metabolic syndrome among adults in Northeast China. Bio Med Central Public Health, 16, 1079-1085. https://doi.org/10.1186/s12889-016-3694-5

4. WHO. Key facts. (2020). https://www.who.int/news-room/fact-sheets/detail/ obesity-and-overweight [Accessed 2 May 2020].

5. Chen G., Yan H., Hao Y., Shrestha S., Wang J., Li Y., Wei Y., Pan J., Zhang Z. (2019). Comparison of various anthropometric indices in predicting abdominal obesity in Chinese children: A cross-sectional study. BioMed Central Pediatrics, 19, 127-133. https://doi.org/10.1186/s12887-019-1501-z

6. Goh L.G.H., Dhaliwal S.S., Welborn T.A., Lee A.H., Della P.R. (2014). Anthropometric measurements of general and central obesity and the prediction of cardiovascular disease risk in women: A cross-sectional study. BMJ Open, 4, e004138. https://doi.org/10.1136/bmjopen-2013-004138

7. Dutra M.T., Reis D.B.V., Martins K.G., Gadelha A.B. (2018). Comparative evaluation of adiposity indices as predictors of hypertension among Brazilian adults. Int J Hypertens, Article ID 8396570. https://doi.org/10.1155/2018/8396570

8. Sangachin M.G, Cavuoto L.A., Wang Y. (2018). Use of various obesity measurement and classification methods in occupational safety and health research: A systematic review of the literature. BioMed Central Obesity, 5, 28-51. https://doi.org/10.1186/s40608-018-0205-5 
9. Hunma S., Ramuth H., Chan J.L.M., Schutz Y., Montani J.P., Joonas N., Dulloo A.G. (2016). Body composition-derived BMI cut-offs for overweight and obesity in Indians and Creoles of Mauritius: Comparison with Caucasians. Int J Obes Suppl, 40, 1906-14. https://doi.org/10.1038/ijo.2016.176

10. Lin T.Y., Lim P.S., Hung S.C. (2018). Impact of misclassification of obesity by body mass index on mortality in patients with CKD. Kidney Int Rep, 3, 447-55. https://doi.org/10.1016/j.ekir.2017.12.009

11. Ghosh K., Sarkar P., Chatterjee D., Bandyopadhyay A.R. (2018). Association of fat patterning, hypertension and ACE (I/D) gene polymorphism: A study on two Tibeto-Burman linguistic groups of Tripura, North East India. MOJ Anat\&Physiol, 5(6), 368-71. https://doi.org/10.15406/mojap.2018.05.00227

12. Mungreiphy N.K., Dhall M., Tyagi R., Saluja K., Kumar A., Tungdim M.G., Sinha R., Rongmei K.S, Tandon K., Bhardwaj S., Kapoor A.K., Kapoor S. (2012). Ethnicity, obesity and health pattern among Indian population. J Nat Sc Biol Med, 3, 52-59. https://doi.org/10.4103/0976-9668.95955

13. Different Tribes of Tripura. https://trci.tripura.gov.in/ [Accessed 5 April 2020 and 27 November 2020]

14. Weiner J.S., Lourie J.A. (1981). Practical human biology. London: Academic Press.

15. World Health Organization. (1995). Physical status: The use and interpretation of anthropometry. Technical report series 854. Geneva: World Health Organization.

16. Fauziana R., Jeyagurunathan A., Abdin E., Vaingankar J., Sagayadevan V., Shafie S., Sambasivam R., Chong S.A., Subramaniam M. (2016). Body mass index, waist-hip ratio and risk of chronic medical condition in the elderly population: Results from the Well-being of the Singapore Elderly (WiSE) Study. BioMed Central Geriatrics, 16(1), 25-33.

https://doi.org/10.1186/s12877-016-0297-z

17. Choi J.R., Koh S.B., Choi E. (2018). Waist-to-height ratio index for predicting incidences of hypertension: The arirang study. BioMed Central Public Health, 18, 767-73. https://doi.org/10.1186/s12889-018-5662-8

18. Morais S.R., Viana A.C., Daltro A.F, Mendonça P. (2018). Cardiovascular risk and use of conicity index in patients submitted to autologous hematopoietic stem cell transplantation. Einstein (São Paulo), 16, 1-5. https://doi.org/10.1590/s1679-45082018ao4253

19. World Health Organization Expert Consultation. (2004). Appropriate bodymass index for Asian populations and its implications for policy and intervention strategies. Lancet, 363, 157-163. https://doi.org/10.1016/S0140-6736(03)15268-3

20. Luke B. (2017). Adverse effects of female obesity and interaction with race on reproductive potential. Fertil Steril, 107, 868-877.

https://doi.org/10.1016/j.fertnstert.2017.02.114 
21. Cossrow N., Falkner B. (2004). Race/ethnic issues in obesity and obesity-related comorbidities. J Clin Endocr Metab, 89(6), 2590-94.

https://doi.org/10.1210/jc.2004-0339

22. Kirby J.B., Liang L., Chen H.J., Wang Y. (2012). Race, place and obesity: The complex relationships among community racial/ethnic composition, individual race/ethnicity, and obesity in the United States. Am J Public Health, 102, 1572-78. https://doi.org/10.2105/AJPH.2011.300452

23. Unal, I. (2017) Defining an Optimal Cut-Point Value in ROC Analysis: An Alternative Approach. Comput Math Methods Med, 2017, 3762651. https://doi.org/10.1155/2017/3762651

24. Sinaga M., Worku M., Yemane T., Tegene E., Wakayo T., Girma T., Lindstrom D., Belachew T. (2018). Optimal cut-off obesity and markers of metabolic syndrome for Ethiopian adults. Nutr J, 17, 109-120. https://doi.org/10.1186/s12937-018-0416-0

25. Hastuti J., Kagawa M., Byrne N.M., Hills A.P. (2017). Determination of new anthropometric cut-off values for obesity screening in Indonesian adults. Asia Pac J Clin Nutr, 26(4), 650-656. https://doi.org/10.6133/apjcn.072016.09

26. Snehalatha C., Viswanathan V., Ramachandran A. (2003). Cutoff values for normal anthropometric variables in Asian Indian adults. Diabetes Care, 26, 1380-1384. https://doi.org/10.2337/diacare.26.5.1380

27. Alberti K.G.M.M., Eckel R.H., Grundy S.M., Zimmet P.Z., Cleeman J.I., Donato K.A., Fruchart J.C., James W.P.T., Loria C.M., Smith S.C. (2009). Harmonizing the metabolic syndrome: A joint interim statement of the International Diabetes Federation Task Force on Epidemiology and Prevention; National Heart, Lung, and Blood Institute; American Heart Association; World Heart Federation; International Atherosclerosis Society; and International Association for the Study of Obesity. Circulation, 120, 1640-45.

https://doi.org/10.1161/CIRCULATIONAHA.109.192644

28. Gadelha A.B., Myers J., Moreira S., Dutra M.T., Safons M.P., Lima R.M. (2016). Comparison of adiposity indices and cut-off values in the prediction of metabolic syndrome in postmenopausal women. Diabetes \& Metabolic Syndrome: Clinical Research \& Reviews, 10, 143-148.

https://doi.org/10.1016/j.dsx.2016.01.005

\section{Address for correspondence:}

Pranabesh Sarkar

Department of Anthropology

University of Calcutta

35 Ballygunge Circular Road, Kolkata-700019, West Bengal, India

E-mail: psanthro_rs@caluniv.ac.in 